Neighbourhood, school and family determinants of children's aspirations

\title{
in primary school
}

Abbreviated title: The role of context in children's aspirations

\author{
Eirini Flouri* \\ Dimitrios Tsivrikos+ \\ Reece Akhtar+ \\ Emily Midouhas* \\ *Institute of Education, University of London \\ +University College London, University of London
}

Correspondence: Eirini Flouri, Department of Psychology and Human Development, Institute of Education, University of London, 25 Woburn Square, London WC1H 0AA, UK. Tel: 0044(0)2076126289; E-mail: e.flouri@ioe.ac.uk 


\begin{abstract}
Aspirations can be important for young children as well as adolescents. However, there is little research on the determinants of aspirations in young children. We carried out this study to investigate the early contextual (neighbourhood, school and family) determinants of the aspirations of young children in the UK. Our sample comprised children of the Millennium Cohort Study who lived in England (for which school-level performance data were available) in the beginning of our study period ( $n=10,086 ; 5,126$ boys). Aspirations were measured at age 7 , and their contextual determinants were measured in the previous data sweeps, at ages 3 and 5 . We fitted structural equation models to test the role of family and neighbourhood socio-economic status (SES) and child ethnicity in predicting aspirations both directly and via their associations with parental involvement, household chaos, school-level achievement and child cognitive ability. We found that the only significant determinants of aspirations at age 7 were family SES and ethnicity, and only in boys. Family SES and ethnicity were also related to parental involvement, household chaos, cognitive ability and school-level achievement, but none of these factors predicted aspirations. Supplementary analysis showed that family SES was a particularly powerful determinant of the aspirations of white compared to non-white boys.
\end{abstract}

Keywords: aspirations; children; family socioeconomic status; neighbourhoods; schools 


\section{Introduction}

Distinct from expectations, aspirations reflect what someone would like to achieve rather than what they think they will achieve. There has been much research on educational or occupational aspirations in adolescence (Bandura, Barbaranelli, Caprara, \& Pastorelli, 2001; Gutman, Schoon, \& Sabates, 2012; Hill et al., 2004; Schoon, Martin, \& Ross, 2007). However, there is evidence that occupational aspirations may be salient for younger children, too. For example, in surveys asking general open-ended questions about aspirations, most children, like adolescents, respond by stating the type of occupation they would like to have rather than general future life states they would hope to achieve (Croll, Attwood, \& Fuller, 2010). In children, aspirations tend to be fantastical and unrealistically high but even adolescents' more realistic aspirations tend to be high. For example, most large-scale studies of adolescent aspirations in the UK have identified aspirations as generally higher than parental achievements or than what the labour market might allow (Croll, 2008). Although researchers have pointed to the generally adverse effect of unrealistically high aspirations (Gorard, Huat See, \& Davies, 2012), most evidence suggest that high aspirations are, in general, associated with positive traits and outcomes, including self-efficacy (Bandura et al., 2001) and value-expectancy beliefs (Frome, Alfeld, Eccles, \& Barber, 2006). However, there is little research on the determinants of aspirations in young children. We carried out this study on the contextual (neighbourhood, school and family) influences on the aspirations of a large cohort of 7 year-olds in the UK to fill this gap.

\subsection{Factors associated with children's aspirations}

According to Gottfredson's (1981) theory of circumscription and compromise, aspirations evolve with age from the fantastical to the concrete, and so, as children grow into adolescents, they revise their aspirations based on their views of their own abilities and interests, as well as on 
societal and parental expectations. Aspirations typically develop in four stages. In stage 1, which can start as early as 3 years, children's aspirations are focussed on size and power. In stage 2 (6-8 years), children become aware of sex and gender differences and begin to eliminate occupations from further consideration if they are not typical for their own sex. Research in the UK and US shows clear sex differences, whereby girls tend to have 'higher' and more intrinsic aspirations than boys as well as greater motivation for school (Schoon, 2001), whereas boys tend to be more adventurous in their dreams, more confident in their abilities, and more likely to aspire to rare jobs (Helwig, 2008). Cognitive ability is another important determinant of aspirations. More masculine aspirations, such as for manual and physical occupations, tend to be associated with lower ability (Creed, Conlon, \& Zimmer-Gembeck, 2007), and aspirations are raised when children are doing well academically (Bond \& Saunders, 1999).

Parents are a major influence on children's aspirations (Jodl, Michael, Malanchuk, Eccles, \& Sameroff, 2001). It has long been established, for example, that children aspire to the careers of their parents at rates significantly above chance (Holland, 1962; Werts \& Watley, 1972), particularly at primary school ages (Trice, Hughes, Odom, Woods, \& McClellan, 1995). Parental education, social class and income, all approximating parental socio-economic status (SES), strongly influence young people's career dreams both directly (Croll, 2008; Schoon \& Parsons, 2002; Mau \& Bikos, 2000) and via their effects on parental involvement and child cognitive ability (Desforges \& Abouchaar, 2003; Muller \& Kerbow, 1993; Stevenson \& Baker, 1987). Ethnicity, associated with both parental SES and involvement, is also related to a range of academic outcomes, including aspirations (Kao \& Thompson, 2003). Research typically finds that minority ethnic children and adolescents have, in general, higher aspirations than their majority white counterparts (Archer, DeWitt, \& Wong, 2013). 
The broader (e.g., school and neighbourhood) context can also influence children's aspirations. Research has shown evidence for both neighbourhood (Leventhal \& Brooks-Gunn, 2000) and school 'effects' (Sellström \& Bremberg, 2006) on a range of child outcomes, even after allowing for families' selective sorting into neighbourhoods and schools. However, most of the research examining these two contexts simultaneously finds that neighbourhood effects are, at least partially, school effects (Owens, 2010), suggesting that schools is the main pathway through which the influence of the neighbourhood may be transmitted to children (Leckie, 2009). Child outcomes related to aspirations such as academic achievement and academic self-concept have been linked mainly to two contextual characteristics, neighbourhood SES (Van Ham, Manley, Bailey, Simpson, \& Maclennan, 2012) and school-level achievement, although not always as intended. For example, Marsh and Hau (2003) have shown that school-level achievement impacts on pupils' academic self-concept negatively, by enabling unfavourable social comparison processes. More recently, Nagengast and Marsh (2012), who tested the relationship between aspirations, academic self-concept and school-level achievement in adolescence, showed that school-level achievement impacted negatively on pupils' career aspirations by lowering academic self-concept.

\subsection{This study}

Drawing on the existing literature discussed above, we attempted to test an integrated model of determinants of aspirations in young children. As can be seen in Figure 1 which shows the hypothesised model, we allowed ethnicity and family and neighbourhood SES to influence aspirations both directly and via their associations with maternal involvement, household chaos, school-level achievement and child cognitive ability. We used mother's involvement in view of the salience of mothers for children at this age, and we allowed household chaos to be a parenting mediator alongside involvement in view of the mediatory role of household chaos in the 
association between SES and child outcomes related to aspirations, such as task persistence (Evans, Gonnella, Marcynyszyn, Gentile, \& Salpekar, 2005) and effortful control (Valiente, Lemery-Chalfant, \& Reiser, 2007).

(Figure 1)

\section{Material and methods}

Our data came from the Millennium Cohort Study (MCS; www.cls.ioe.ac.uk/mcs), a longitudinal survey of 19,244 families drawing its sample from all births in the UK over a year, from 1 September 2000. MCS was designed to over-represent areas with high proportions of ethnic minorities in England, areas of high child poverty, and the three smaller UK countries. The MCS sample is disproportionately stratified, firstly by country, and then type of electoral ward within which all the year's births were eligible ${ }^{1}$. Sweep 1 took place when the children were around 9 months, and Sweeps 2, 3, and 4 took place around ages 3, 5, and 7. We analysed data from Sweeps 2-4. We used records for only one child per family (the first-born where there were twins or triplets). Our analytic sample comprised children living in England (for which school-level performance data were available) at age 3 ( $n=10,086 ; 5,126$ boys).

\subsection{Measures}

Occupational orientation at age 7 was measured as a latent factor based on three manifest ordinal items measuring the following characteristics of the child's aspiration: prestige, femininity/masculinity, and level of intrinsic/extrinsic motivation (Flouri, Moulton, \& Panourgia, 2012). Although this factor was found to have low levels of internal consistency $(\alpha=.28)$, a Principal

\footnotetext{
${ }^{1}$ Electoral wards/divisions are the key building block of UK electoral geography. The average population is around 5,000 , though counts can vary substantially. The sample was drawn on the basis of boundaries that existed before the 2001 Census. This geography was no longer applied once the survey started.
} 
Components Analysis (PCA) showed that the variables represented a single factor that accounted for $40 \%$ of the variance. A higher score on this factor was related to a less prestigious, more masculine and more extrinsic aspiration (e.g., 'footballer') and a lower score to a more prestigious, more feminine and more intrinsic aspiration (e.g., 'teacher'). To rank on prestige, the Standard Occupation Classification 2000 (SOC2000) from the Office for National Statistics was used. SOC2000 classifies occupations into 9 major (and 353 unit) groups from the highest to the lowest level of occupational status, which we aggregated into five: I) Managers \& Senior Officials and Professional Occupations; II) Associate Professional and Technical Occupations; III) Administrative and Secretarial \& Skilled Trades Occupations; IV) Personal Service \& Sales and Customer Service Occupations, and V) Process, Plant and Machine Operatives \& Elementary Occupations. The femininity/masculinity of each occupational aspiration was coded using the proportion of UK working-age women in that occupation. Following Sullivan, Joshi, and Leonard (2011), the following cutoffs were used: "masculine" (<25\% women), "integrated" ( $25 \%$ to $49.9 \%$ women), "feminine" (50\%-74.9\% women), and "ultra-feminine" (>=75\% women). The \% value was the proportion of UK women in that occupation (4-digit SOC2000 Unit Group, where possible) using the Labour Force Survey data for 2008 , the same year the MCS children were asked about their aspirations. Where information about the percentage of UK working-age women in an aspired occupation was not available for a particular unit group in SOC2000, the most detailed classification available was used. For aspiration categories where no SOC2000 classification could be given (e.g., for fantasy responses or social roles), an appropriate gender category was allocated where possible. For example, responses such as "mum" and "dad" were coded as "ultra-feminine" and "masculine," respectively. Where no inference could be made about the masculinity/femininity of the aspiration (for example, "happy"), the response was coded as missing information on masculinity/femininity. Finally, each aspiration was classified into "intrinsic-intermediate," "neutral," "extrinsic- 
intermediate," or "extrinsic." Aspirations were not coded to the usual dichotomy of extrinsic vs. intrinsic goals because in the fourth sweep of MCS children were asked what they would like to be when they grow up, but not the reasons for their aspirations. Instead, this coding scheme broadly reflected 'the self-determination continuum' (Ryan \& Deci, 2000). Extrinsic aspirations were those that could be motivated by materialistic goals or concerns about image, power or popularity, such as "supermodel," "billionaire" or "popstar." Extrinsic-intermediate aspirations were goals that could reflect concerns about or preoccupations with financial success, image, praise or popularity (e.g., "actor," "singer or "fashion designer"). There were very few children who, unprompted, gave responses reflecting intrinsic goals such as community (e.g., "look after poor people"). Therefore, these aspirations were merged with those which could be intrinsically-motivated as they involved helping or caring for people or animals, such as "nurse," "vet," "teacher" or "doctor." All such responses were coded as intrinsic-intermediate. Aspirations that could not be identified as extrinsic, extrinsic-intermediate or intrinsic-intermediate, such as "farmer," were coded as "neutral" (but also included in the analysis). Intrinsic aspirations were associated with child prosocial behaviour. Based on the $95 \% \mathrm{Cl}$ of weighted prosocial behaviour means, MCS children with 'intrinsic-intermediate' aspirations had significantly higher prosocial behaviour scores than other children.

The child-level variables were sex and ethnicity, coded as white and non-white.

Family socio-economic status (SES) was measured at Sweep 2 as a latent factor comprising five manifest binary items: 1) mother in a Higher/Lower Professional, Administrative or Managerial occupation (the highest social class according to the UK Government's National Statistics Socioeconomic Classification [NS-SEC]), 2) father in a Higher/Lower Professional, Administrative or Managerial occupation, 3) mother with the National Vocational Qualification (NVQ) equivalent to a university degree, 4) father with the NVQ equivalent to a university degree, and 5) family income 
above the poverty line, set at $60 \%$ of the national median income. The five items formed a scale of good internal consistency $(\alpha=.74)$, and loaded on a single factor that accounted for $52 \%$ of the variance. Neighbourhood socio-economic status (SES) was measured at Sweep 2 as a latent factor with three manifest items: 1 ) \% of adult residents in the Lower layer Super Output Area (LSOA) ${ }^{2}$ with a Higher/Lower Professional, Administrative or Managerial occupation (banded in quintiles), 2) $\%$ of adult residents with the NVQ equivalent to a university degree in the LSOA in quintiles, and 3) 2004 Index of Multiple Deprivation (IMD) income deprivation score for the LSOA in deciles. This score is a relative score of within-England ranking of income deprivation of families' neighbourhoods. The five-item scale had a good level of internal consistency $(\alpha=.94)$, and a PCA revealed a single factor that accounted for $90 \%$ of the variance.

The age 5 mediators were child's cognitive ability, the family-level variables of mother's involvement and household chaos, and school-level achievement. Cognitive ability was measured as a latent factor of the British Ability Scales II (BASII) scores in pattern construction, picture similarities, and naming vocabulary. Pattern construction and picture similarities assess non-verbal ability (spatial realisation and reasoning ability, respectively), and naming vocabulary assesses language skills. Maternal involvement was measured as a latent factor with six items of how frequently the mother engages in the following activities with the child: reading, telling stories, doing musical activities, painting/drawing, playing physically active games, and playing games/toys indoors $(\alpha=.71)$. All items were measured on a 5 -point scale from 1 (every day) to 5 (never). Household chaos was assessed as a latent factor using five manifest items ( $\alpha=.59$ ). The first three are from a shortened version of the valid and reliable Confusion, Order and Hubbub scale (Matheny, Wachs, Ludwig, \& Phillips, 1995), administered to the main respondent. The three items

\footnotetext{
${ }^{2}$ LSOAs are built from groups of Census Output Areas (typically 4-6), and are constrained by the boundaries of the Standard Table wards used for Census outputs. They have, on average, 1,500 residents and are generally smaller than wards.
} 
are: "the atmosphere in my home is calm", "I can't hear myself think in my home", and "it is really disorganised in our home". The other two items measured parent-reported regularity of child's bedtime and mealtimes on a Likert 8-point scale from 0 (not occurring) to 7 (very frequent). Each of these three scaled variables was subjected to a PCA, revealing single factors that accounted for $38 \%$ (household chaos), 42\% (maternal involvement) and 56\% (cognitive ability) of the variance.

School-level achievement was measured as the achievement of schools attended by MCS children at around age 5. This was assessed with the school-level Key Stage 1 (KS1) 3 average point scores of state-maintained schools, collected during the January 2006 Census and obtained from the Schools Data Unit at the Department for Education. KS1 assessments are not administered to pupils until the end of year 2 of school. Therefore, these KS1 data apply to a different cohort of children than the MCS children.

Area stratum was adjusted in all models to reflect the stratified sampling design of MCS from pre-2001 wards. There were 3 England strata: England-advantaged, England-disadvantaged, and England-Ethnic.

\section{Results}

Structural Equation Modelling was used to investigate the predictive influence of ethnicity, family and neighbourhood SES, quality of the school and the home environment, and child's cognitive ability on occupational orientation. Structural Equation Models (SEMs) were fitted in Amos 5.0 (Arbuckle, 2003). Descriptive statistics and bivariate correlations between the observed variables are shown in Table 1. As can be seen, the correlations between sex and the three aspiration variables were significant but they varied in strength. Prestige had the weakest

\footnotetext{
${ }^{3}$ In England, key stages are stages of the state education system. KS1 applies to ages 5-7 (years 1-2). Children are assessed in English, Maths, and Science at the end of KS1. KS1 data are only available for state-maintained schools, and therefore these data were missing for those MCS children not attending state schools (around $8 \%$ of our sample).
} 
correlation $(r=.07)$ with female sex, and masculinity the strongest $(r=-.61)$. While, in general, aspirations were not related to maternal involvement or household chaos, all but one (income poverty) family SES variables were significantly associated with prestige. By contrast, cognitive ability did not correlate with prestige, although it was (negatively) associated with masculinity. The three manifest aspiration variables were inter-correlated, albeit weakly.

(Table 1)

The hypothesised model (Figure 1) featured six latent constructs, representing family SES, neighbourhood SES, household chaos, mother's involvement, and child's cognitive ability and occupational orientation. In the hypothesised model, family SES, neighbourhood SES, and ethnicity were exogenous variables. Maternal involvement, household chaos, cognitive ability and schoollevel achievement were exogenous and endogenous, and occupational orientation was endogenous. All within sweep variables were allowed to covary with each other. The MCS stratified sampling design was accounted for by including area stratum as a covariate. Using the multigroup analysis function in Amos, the model's paths were allowed to be moderated by child's sex.

The model's goodness of fit was assessed with the $\chi^{2}$ statistic, the Tucker Lewis Index (TLI), the Comparative Fit Index (CFI), and the Root Mean Square Error of Approximation (RMSEA). Missing data were estimated using the Full Information Maximum Likelihood (FIML) method. In order to test for moderation, the 'Critical Ratios for Differences' Amos function was used alongside Gaskin's (2012) StatsTool statistics package. This function is analogous to a standard $t$-test as it tests for group differences by comparing the effect sizes of each regression path, and produces a $z$ statistic that can then be used to determine significant differences. The hypothesised model's fit was acceptable $\left(\chi^{2}(668)=5223.55 ; p<.001 ; \mathrm{TFI}=.93 ; \mathrm{CFI}=.94 ; \mathrm{RMSEA}=.03\right)$, but attempts were made to identify any misspecifications. 
In order to improve the model's fit, expected parameter change and standardised residuals were inspected and fit statistics investigated when regression paths and covariances were deleted or added to the model. Paths from household chaos, maternal involvement, neighbourhood SES, school-level achievement and cognitive ability to occupational orientation were not significant and were therefore removed from the model, as was the covariance between ethnicity and SES.

Neighbourhood SES was allowed to predict only school-level achievement. Family SES was allowed to covary with neighbourhood SES, household chaos with maternal involvement, and cognitive ability with school-level achievement. These modifications did not improve the model's fit ( $\chi^{2}(690)$ $=5499.12, p<.001 ; \mathrm{TLI}=.93 ; \mathrm{CFI}=.94 ; \mathrm{RMSEA}=.03)$, but were kept for model parsimony. Table 2 lists the standardised path estimates for boys and girls, and the variance explained in each endogenous construct.

(Table 2)

As illustrated in Table 2, the relationship between both family SES and ethnicity with occupational orientation was significant only in boys. Nonetheless, there were no sex differences in the effects of our exogenous variables on school-level achievement, household chaos or maternal involvement. There was, however, a significant sex difference in the relationship between ethnicity and cognitive ability, such that the positive effect of white ethnicity was significantly stronger on boys' compared to girls' cognitive ability.

\subsection{Supplementary analysis}

Given the moderation of the effect of ethnicity on occupational orientation by sex, we explored further the sex by ethnicity interaction. We therefore fitted a four-group SEM. The four groups were White Boys $(N=3848)$, White Girls $(N=3717)$, Non-White Boys $(N=1268)$, and Non- 
White Girls $(N=1236)^{4}$. Replicating the previous analysis, the original hypothesised model was tested with the exception that ethnicity was no longer an exogenous variable. This model fitted the data $\left(X^{2}(1248)=5288.57, p<.001 ; \mathrm{TLI}=.92 ; \mathrm{CFI}=.94 ; \mathrm{RMSEA}=.02\right)$, but steps were taken to improve the model's fit by removing any misspecifications. This resulted in making the same changes as those made in the two-group model. After making these changes, the fit improved ( $X^{2}$ $(1308)=4334.86, p<.001 ; \mathrm{TLI}=.95 ; \mathrm{CFI}=.96 ; \mathrm{RMSEA}=.02)$. Table 3 lists the standardised path estimates for the four groups of children, and the variance explained in each endogenous construct.

(Table 3)

When comparing the four-group with the two-group SEM, it is interesting to note the substantial increase in the amount of explained variance in occupational orientation among white boys compared to the other groups of children. As can be seen, the relationship between family SES and occupational orientation was significant only in white boys and nonsignificant in all other groups. Another noteworthy finding is the consistent relationship of family SES with cognitive ability, maternal involvement, household chaos and school-level achievement across all four groups.

\section{Discussion and conclusions}

We carried out this study to explore simultaneously the role of neighbourhood, school and family influences on the aspirations of seven-year-old children in the UK. Following a large cohort of children in England from age 3 to age 7, we allowed aspirations to be predicted directly by ethnicity, family SES and neighbourhood SES, and indirectly by parenting, cognitive ability and school 'quality'. Our study found no evidence for the role of neighbourhood SES or for any of these mediators in predicting children's aspirations. Aspirations in our study were predicted only by

\footnotetext{
${ }^{4}$ For 17 children we had no information about ethnicity.
} 
family SES and ethnicity, and only in boys. Boys from ethnic minority families and those from higher SES had more 'white-collar' aspirations than white and lower SES boys, respectively. Importantly, family SES predicted aspirations only in white boys. Together, our study findings suggest that, in England, 7-year-old boys' aspirations are directly shaped by their parents' educational, economic and ethnic backgrounds. The lack of evidence for 'process paths' from SES to aspirations (i.e., via parenting and child cognitive ability) or for distal influences (i.e., of neighbourhoods or schools) on aspirations suggests that, in our sample, white boys' early aspirations were influenced directly by their parents' levels of education and material resources, and not because parents' education, social class or income were related to more involved parenting or higher quality (home, school or neighbourhood) environments for their children. The roles of ethnicity and SES in aspirations were also robust to adjustment for cognitive ability, which suggests that family SES and ethnicity were associated directly with the type of aspirations expressed by boys, and not because of SES and ethnicity differences in cognitive ability in children. Socio-economic status and ethnicity differences did not explain differences in the aspirations expressed by girls. It appears, therefore, that, in girls, family background, at least as we measured it, is less important in determining the career dreams expressed early in life.

The limitations of our study should be noted. Girls had higher, more intrinsic and more feminine aspirations than boys, but our model did not predict them. Another important limitation is the classification of aspirations on limited data. We ranked children's aspirations on masculinity/femininity and prestige using official data on the sex segregation and prestige of the occupations of the UK working-age population in the same year the MCS children were asked about their aspirations. However, it may be that to a 7-year-old 'train driver' is a more prestigious occupation than 'teacher', for example. Similarly, we ascribed intrinsic/extrinsic occupational and life goals to children without having data on the children's reasons for them. For example, 'doctor' 
may be an extrinsic goal if the motivation is the high status and public prestige usually enjoyed by doctors, but intrinsic if the motivation is to help those in need. Finally, we did not have information about children's exposure to people with different kinds of occupations, which likely covaries with parental background.

Despite these limitations, our study has many strengths. This was the first study to examine simultaneously the role of several contextual factors in young children's aspirations. Its additional strengths are the use of a large, nationally representative cohort of children followed from early to middle childhood, and the simultaneous examination of several aspiration domains. This examination confirmed that, even in young children, aspirations tend to be constrained by parental background, but also uncovered important sex differences in its influence. 


\section{Acknowledgements:}

This research was supported by a grant to the UK Economic and Social Research Council (grant ES/J001414/1). 


\section{References}

Arbuckle, J. (2003). Amos 5.0 Update to the Amos User's Guide. Chicago, IL: Smallwaters Corporation.

Archer, L., DeWitt, J., \& Wong, B. (2013). Spheres of influence: What shapes young people's aspirations at age 12/13 and what are the implications for education policy? Journal of Education Policy, 29, 58-85.

Bandura, A., Barbaranelli, C., Caprara, G. V. \& Pastorelli, C. (2001). Self-efficacy beliefs as shapers of children's aspirations and career trajectories. Child Development, 72, 187-206.

Bond, R., \& Saunders, P. (1999). Routes of success: Influences on the occupational attainment of young British males. British Journal of Sociology, 50, 217-249.

Creed, P. A., Conlon, E. G., \& Zimmer-Gembeck, M. J. (2007). Career barriers and reading ability as correlates of career aspirations and expectations of parents and their children. Journal of Vocational Behavior, 70, 242-258.

Croll, P. (2008). Occupational choice, socio-economic status and educational attainment: A study of the occupational choices and destinations of young people in the British Household Panel Survey. Research Papers in Education, 23, 243-268.

Croll, P., Attwood, G., \& Fuller, C. (2010). Children's lives, children's futures. London: Continuum. Desforges, C., \& Abouchaar, A. (2003). The impact of parental involvement, parental support and family education on pupil achievement and adjustment: A review of the literature. Research Report 433. London: DfES.

Evans, G. W., Gonnella, C., Marcynyszyn, L. A., Gentile, L., \& Salpekar, N. (2005). The role of chaos in poverty and children's socioemotional adjustment. Psychological Science, 16, 560-565.

Flouri, E., Moulton, V., \& Panourgia, C. (2012). Coding the aspirations of children at age 7 in the Millennium Cohort Study. MCS data note. London: Centre for Longitudinal Studies. 
Frome, P. M., Alfeld, C. J., Eccles, J. S., \& Barber, B. L. (2006). Why don't they want a maledominated job? An investigation of young women who changed their occupational aspirations. Educational Research and Evaluation, 12, 359-372.

Gaskin, J. (2012). Group Differences. Stats Tools Package, http://statwiki.kolobkreations.com

Gorard, S., Huat See, B., \& Davies, P. (2012). The impact of attitudes and aspirations on educational attainment and participation. York: Joseph Rowntree Foundation.

Gottfredson, L. S. (1981). Circumspection and compromise: A developmental theory of occupational aspirations. Journal of Counseling Psychology Monographs, 28, 545-579.

Gutman, L. M., Schoon, I., \& Sabates, R. (2012). Uncertain aspirations for continuing in education: Antecedents and associated outcomes. Developmental Psychology, 48, 1707-1718.

Helwig, A. A. (2008). From childhood to adulthood: A 15-year longitudinal career development study. The Career Development Quarterly, 57, 38-50.

Hill, N. E., Castellino, D. R., Lansford, J. E., Nowlin, P., Dodge, K. A., Bates, J. E., \& Pettit, G. S. (2004). Parent academic involvement as related to school behavior, achievement, and aspirations: Demographic variations across adolescence. Child Development, 75, 1491-1509.

Holland, J. L. (1962). Some explorations of a theory of vocational choice: I. One- and two-year longitudinal studies. Psychological Monographs, 76, (Whole No. 545).

Jodl, K. M., Michael, A., Malanchuk, O., Eccles, J. S., \& Sameroff, A. (2001). Parents' roles in shaping early adolescents' occupational aspirations. Child Development, 72, 1247-1266.

Kao, G., \& Thompson, J. S. (2003). Racial and ethnic stratification in educational achievement and attainment. Annual Review of Sociology, 29, 417-442.

Leckie, G. (2009). The complexity of school and neighbourhood effects and movements of pupils on school differences in models of educational achievement. Journal of the Royal Statistical Society: Series A (Statistics in Society), 172, 537-554. 
Leventhal, T., \& Brooks-Gunn, J. (2000). The neighborhoods they live in: The effects of neighborhood residence on child and adolescent outcomes. Psychological Bulletin, 126, 309337.

Marsh, H. W., \& Hau, K. T. (2003). Big-Fish-Little-Pond effect on academic self-concept: A crosscultural (26-country) test of the negative effects of academically selective schools. American Psychologist, 58, 364-376.

Matheny Jr, A. P., Wachs, T. D., Ludwig, J. L., \& Phillips, K. (1995). Bringing order out of chaos: Psychometric characteristics of the confusion, hubbub, and order scale. Journal of Applied Developmental Psychology, 16, 429-444.

Mau, W. C., \& Bikos, L. H. (2000). Educational and vocational aspirations of minority and female students: A longitudinal study. Journal of Counseling and Development, 78, 186-194.

Muller, C., \& Kerbow, D. (1993). Parent involvement in the home, school, and community. In Parents, their children, and schools, edited by B. Schneider and J. S. Coleman. Boulder, CO: Westview.

Nagengast, B., \& Marsh, H. W. (2012). Big fish in little ponds aspire more: Mediation and crosscultural generalizability of school-average ability effects on self-concept and career aspirations in science. Journal of Educational Psychology, 104, 1033-1053.

Owens, A. (2010). Neighborhoods and schools as competing and reinforcing contexts for educational attainment. Sociology of Education, 83, 287-311.

Ryan, R. M., \& Deci, E. L. (2000). Self-determination theory and the facilitation of intrinsic motivation, social development, and well-being. American Psychologist, 55, 68-78.

Schoon, I. (2001). Teenage job aspirations and career attainment in adulthood: A 17-year follow-up study of teenagers who aspired to become scientists, health professionals, or engineers. International Journal of Behavioral Development, 25, 124-132. 
Schoon, I., Martin, P., \& Ross, A. (2007). Career transitions in times of social change: His and her story. Journal of Vocational Behavior, 70, 78-96.

Schoon, I., \& Parsons, S. (2002). Teenage aspirations for future careers and occupational outcomes. Journal of Vocational Behavior, 60, 262-288.

Sellström, E., \& Bremberg, S. (2006). Is there a "school effect" on pupil outcomes? A review of multilevel studies. Journal of Epidemiology and Community Health, 60, 149-155.

Stevenson, D. L., \& Baker, D. P. (1987). The family-school relation and the child's school performance. Child Development, 58, 1348-1357.

Sullivan, A., Joshi, A., \& Leonard, D. (2011). Single-sex schooling and labour market outcomes. Oxford Review of Education, 37, 311-332.

Trice, A. D., Hughes, M. A., Odom, C., Woods, K., \& McClellan, N. C. (1995). The origins of children's career aspirations: IV. Testing hypotheses from four theories. The Career Development Quarterly, 43, 307-322.

Valiente, C., Lemery-Chalfant, K., \& Reiser, M. (2007). Pathways to problem behaviors: Chaotic homes, parent and child effortful control, and parenting. Social Development, 16, 249-267. van Ham, M., Manley, D., Bailey, N., Simpson, L., \& Maclennan, D. (Eds.) Neighbourhood effects research: New perspectives. Netherlands: Springer.

Werts, C. E., \& Watley, D. J. (1972). Paternal influence on talent development. Journal of Counseling Psychology, 19, 367-372. 
Table 1: Bivariate correlations and descriptive statistics (key observed variables)

\begin{tabular}{|c|c|c|c|c|c|c|c|c|c|c|c|c|c|c|c|c|c|c|c|c|c|c|c|c|c|c|c|c|c|c|c|}
\hline & & 1. & 2. & 3. & 4. & 5. & 6. & 7. & 8. & 9. & 10. & 11. & 12. & 13. & 14. & 15. & 16. & 17. & 18. & 19. & 20. & 21. & 22. & 23. & 24. & 25. & 26. & 27. & Mean & SD & N \\
\hline 1. & Girl & - & & & & & & & & & & & & & & & & & & & & & & & & & & & 1.49 & .50 & 10086 \\
\hline 2. & Non-white & .00 & - & & & & & & & & & & & & & & & & & & & & & & & & & & 1.50 & .86 & 10069 \\
\hline 3. & $\begin{array}{l}\text { Low } \\
\text { neighbourhood } \\
\text { income } \\
\text { deprivation }\end{array}$ & .00 & $-.37 * *$ & - & & & & & & & & & & & & & & & & & & & & & & & & & 4.87 & 3.01 & 8883 \\
\hline 4. & $\begin{array}{l}\text { Neighbourhood } \\
\text { social class }\end{array}$ & .00 & $-.29 * *$ & $.91^{* *}$ & - & & & & & & & & & & & & & & & & & & & & & & & & 5.03 & 2.97 & 8883 \\
\hline 5. & $\begin{array}{l}\begin{array}{l}\text { Neighbourhood } \\
\text { education }\end{array}\end{array}$ & .01 & $-.19 * *$ & $.83^{* *}$ & $.81^{* *}$ & - & & & & & & & & & & & & & & & & & & & & & & & 4.82 & 2.97 & 8883 \\
\hline 6. & $\begin{array}{l}\text { Low maternal } \\
\text { social class }\end{array}$ & -.01 & $.08^{* *}$ & $.37^{* *}$ & $.35^{* *}$ & $.41^{* *}$ & - & & & & & & & & & & & & & & & & & & & & & & 4.09 & 2.01 & 8526 \\
\hline 7. & $\begin{array}{l}\text { Low paternal } \\
\text { social class }\end{array}$ & .00 & $.14^{* *}$ & $.42^{* *}$ & $.42^{* *}$ & $.46^{* * *}$ & $.40^{* * *}$ & - & & & & & & & & & & & & & & & & & & & & & 3.78 & 2.05 & 7671 \\
\hline 8. & $\begin{array}{l}\text { Low maternal } \\
\text { education }\end{array}$ & -.01 & $.23^{* *}$ & $.43^{* *}$ & $.41^{* *}$ & $.44^{* *}$ & $.53^{* *}$ & $.43^{* *}$ & - & & & & & & & & & & & & & & & & & & & & 4.14 & 1.71 & 9383 \\
\hline 9. & $\begin{array}{l}\begin{array}{l}\text { Low paternal } \\
\text { education }\end{array} \\
\text { late }\end{array}$ & -.01 & $.13^{* *}$ & $.36^{* *}$ & $.36^{* *}$ & $.42^{* *}$ & $.39^{* * *}$ & $.56^{* * *}$ & $.51^{* *}$ & - & & & & & & & & & & & & & & & & & & & 4.05 & 1.81 & 7192 \\
\hline 10. & $\begin{array}{l}\text { Family in } \\
\text { poverty }\end{array}$ & .00 & $.26^{* *}$ & $.45^{* *}$ & $.43^{* *}$ & $.40^{* *}$ & $.39 * *$ & $.35 * *$ & $.43^{* *}$ & $.36^{* *}$ & - & & & & & & & & & & & & & & & & & & .32 & .47 & 8597 \\
\hline 11. & $\begin{array}{l}\text { Picture } \\
\text { similarity score }\end{array}$ & $.06^{* *}$ & $-.06^{* *}$ & $.13^{* *}$ & $.13^{* *}$ & $.14^{* *}$ & $.15^{* *}$ & $.15^{* * *}$ & $.18^{* *}$ & $.18^{* *}$ & $.13^{* *}$ & - & & & & & & & & & & & & & & & & & 55.33 & 10.1 & 8765 \\
\hline 12. & $\begin{array}{l}\text { Naming } \\
\text { vocabulary } \\
\text { score }\end{array}$ & $.03^{* *}$ & $-40^{* *}$ & $.36^{* *}$ & $.31^{* * *}$ & $.30^{* * *}$ & $.29^{9 * *}$ & $.29^{* * *}$ & $.40^{* *}$ & $.32^{* *}$ & $.33^{* *}$ & $.31^{* *}$ & - & & & & & & & & & & & & & & & & 53.49 & 11.57 & 8770 \\
\hline 13. & 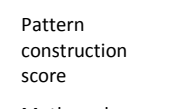 & $.10^{* *}$ & $-14^{* *}$ & $.20^{* * *}$ & $.18^{* *}$ & $.18^{* *}$ & $.16^{* *}$ & $.18^{* *}$ & $.24^{* *}$ & $.19^{* *}$ & $.19^{* *}$ & $.35^{* *}$ & $.36^{* *}$ & - & & & & & & & & & & & & & & & 50.32 & 10.00 & 8745 \\
\hline 14. & $\begin{array}{l}\text { Mothers does } \\
\text { not read to } \\
\text { child }\end{array}$ & .00 & $.16^{* *}$ & $.18^{* *}$ & $.16^{* *}$ & $.16^{* *}$ & $.15^{* *}$ & $.16^{* *}$ & $.25^{* *}$ & $.20^{* *}$ & $.16^{* *}$ & $.08^{* *}$ & $.22^{* *}$ & $.11^{* *}$ & - & & & & & & & & & & & & & & 1.84 & 1.09 & 8869 \\
\hline 15. & $\begin{array}{l}\text { Mother does } \\
\text { not tell stories } \\
\text { to child }\end{array}$ & $-02^{*}$ & $-04^{* *}$ & .02 & $.03^{*}$ & .00 & $.03^{* *}$ & .00 & $.04 * *$ & .02 & -.01 & -0.02 & $.04 * *$ & .00 & . $19 * *$. & - & & & & & & & & & & & & & 3.51 & 1.54 & 8865 \\
\hline
\end{tabular}


Mothers does activities with

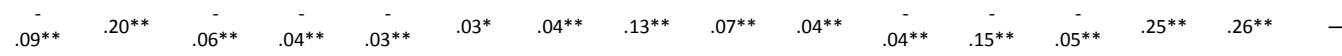

Motherdos

$\begin{array}{llllllllllllllllll}\text { Mother does } & - & .07^{* *} & -.02 & .00 & -.02^{*} & .03^{*} & .04^{* *} & .08^{* *} & .07^{* *} & .04^{* *} & .04^{* *} & .10^{* *} & .06^{* *} & .31^{* *} & .29^{* *} & .32^{* *} & -\end{array}$

Mother does

not play

physical games

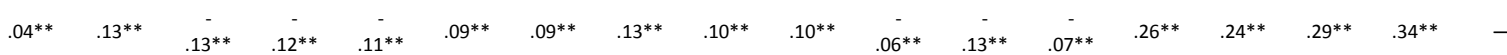

Mother do

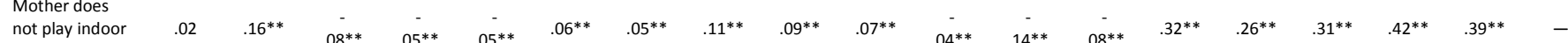

Home is

Home is
organised

$.02^{*} \quad .04 * *$

Home is not
noisy

$.04 * * \quad .06 * *$

$\begin{array}{lllllllll}.09^{* *} & .08^{* *} & .09 * * & - & - & - & - & - & - \\ & & & -07^{* *} & .07 * & .07 * & .07^{* *} & .10^{* *} & .04 * *\end{array}$

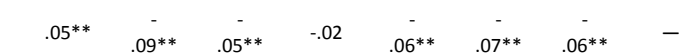

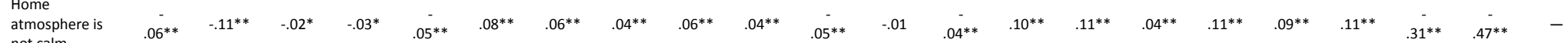

23. Regular

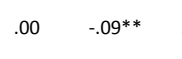

$.10^{* *} \quad .09 *$

Regular
mealtimes

$.00 \quad-.09 * *$

$.13^{* *}$

$.09 * *$

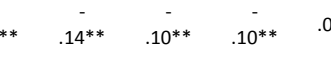

$.12^{* *} \quad .09$

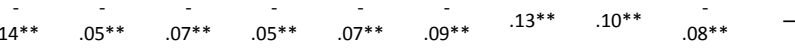

School-level
achievement

$.00 \quad-.28^{* *} \quad .51^{* *}$

$\begin{array}{lccc}\text { Low prestige of } & - & -.11^{* *} & .02 \\ \text { aspiration } & .07^{* *} & & \end{array}$

Masculinity of

aspiration

$.61^{* *} \quad-.01$

Extrinsic motivation
aspiration

Note: ${ }^{*} p<.05 ;{ }^{* *} p<.01$. Neighbourhood SES = Rows 3-5. Family SES = Rows 6-10. Cognitive Ability = 11-13. Maternal Involvement $=$ Rows $14-19$. Household Chaos $=$ Rows 20-24. Occupational Orientation = Rows 26-28. 


\begin{tabular}{|c|c|c|c|c|}
\hline & & Boys $(n=5,126)$ & Girls $(n=4,960)$ & Pairwise Comparison \\
\hline Endogenous Variables & Exogenous Variables & 8 & 8 & $z$ \\
\hline \multirow[t]{3}{*}{ (Low) Household Chaos } & & $13 \%$ & $13 \%$ & \\
\hline & (Low) Family SES & $-.37 * *$ & $-.36 * *$ & .217 \\
\hline & Non-white Ethnicity & $.09 * *$ & $.14^{* *}$ & 1.153 \\
\hline \multirow{3}{*}{$\begin{array}{l}\text { (Low) Maternal } \\
\text { Involvement }\end{array}$} & & $9 \%$ & $10 \%$ & \\
\hline & (Low) Family SES & $.23^{* *}$ & $.23^{* *}$ & .028 \\
\hline & Non-white Ethnicity & $.15^{* *}$ & $.16^{* *}$ & .311 \\
\hline \multirow[t]{3}{*}{ Cognitive Ability } & & $43 \%$ & $44 \%$ & \\
\hline & (Low) Family SES & $-.50 * *$ & $-.51^{* *}$ & 1.285 \\
\hline & Non-white Ethnicity & $-.30 * *$ & $-.25 * *$ & $2.603^{* *}$ \\
\hline \multirow[t]{4}{*}{ School-level Achievement } & & $31 \%$ & $33 \%$ & \\
\hline & Neighbourhood SES & $.34 * *$ & $.32 * *$ & -.420 \\
\hline & (Low) Family SES & $-.23 * *$ & $-.27 * *$ & -1.306 \\
\hline & Non-white Ethnicity & $-.09 * *$ & $-.10 * *$ & -.301 \\
\hline \multirow{3}{*}{$\begin{array}{c}\text { ('Blue-collar') Occupational } \\
\text { Orientation }\end{array}$} & & $35 \%$ & $0 \%$ & \\
\hline & (Low) Family SES & $.55 * *$ & -.04 & $-4.905 * *$ \\
\hline & Non-white Ethnicity & $-.38 * *$ & -.05 & $2.578^{* *}$ \\
\hline
\end{tabular}

Note: The percentage of accounted variance in each endogenous variable is in bold, and was computed using the Squared Multiple Correlations function in Amos; $6=$ standardised regression coefficient; ${ }^{* *} p<.01$. 
Table 3: Sex by ethnicity differences in SEM paths

\begin{tabular}{|c|c|c|c|c|c|}
\hline & & \multicolumn{4}{|c|}{ Models } \\
\hline & & WB & WG & NWB & NWG \\
\hline Endogenous Variables & Exogenous Variables & 8 & 8 & 8 & 8 \\
\hline \multirow[t]{2}{*}{ (Low) Household Chaos } & & $13 \%$ & $14 \%$ & $11 \%$ & $8 \%$ \\
\hline & (Low) Family SES & $-.35^{* *}$ & $-.37 * *$ & $-.35 * *$ & $-.28 * *$ \\
\hline \multirow[t]{2}{*}{ (Low) Maternal Involvement } & & $3 \%$ & $3 \%$ & $9 \%$ & $8 \%$ \\
\hline & (Low) Family SES & $.18^{* *}$ & $.19 * *$ & $.29 * *$ & $.27^{* *}$ \\
\hline \multirow[t]{2}{*}{ Cognitive Ability } & & $35 \%$ & $38 \%$ & $38 \%$ & $44 \%$ \\
\hline & (Low) Family SES & $-.59 * *$ & $-.61^{* *}$ & $-.61 * *$ & $-.66 * *$ \\
\hline \multirow[t]{3}{*}{ School-level Achievement } & & $25 \%$ & $28 \%$ & $25 \%$ & $26 \%$ \\
\hline & Neighbourhood SES & $.32 * *$ & $.31 * *$ & $.33 * *$ & $.32 * *$ \\
\hline & (Low) Family SES & $-.24 * *$ & $-.28 * *$ & $-.23 * *$ & $-.26 * *$ \\
\hline \multirow[t]{2}{*}{$\begin{array}{c}\text { ('Blue-collar') Occupational } \\
\text { Orientation }\end{array}$} & & $49 \%$ & $0 \%$ & $2 \%$ & $0 \%$ \\
\hline & (Low) Family SES & $.70 * *$ & -.04 & .14 & .01 \\
\hline
\end{tabular}

Note: $\mathrm{WB}=$ White Boys, $\mathrm{WG}=$ White Girls, NWB = Non-White Boys, NWG = Non-White Girls. The percentage of accounted variance in each endogenous variable is in bold, and was computed using the Squared Multiple Correlations function in Amos; $6=$ standardised regression coefficient; ${ }^{* *} p<.01$. 
Figure 1: The hypothesised model.

Note: Dotted lines represent paths that were later removed to improve model fit. For illustrative simplicity, the loadings for latent constructs, covariances and area stratum effects are not shown. 


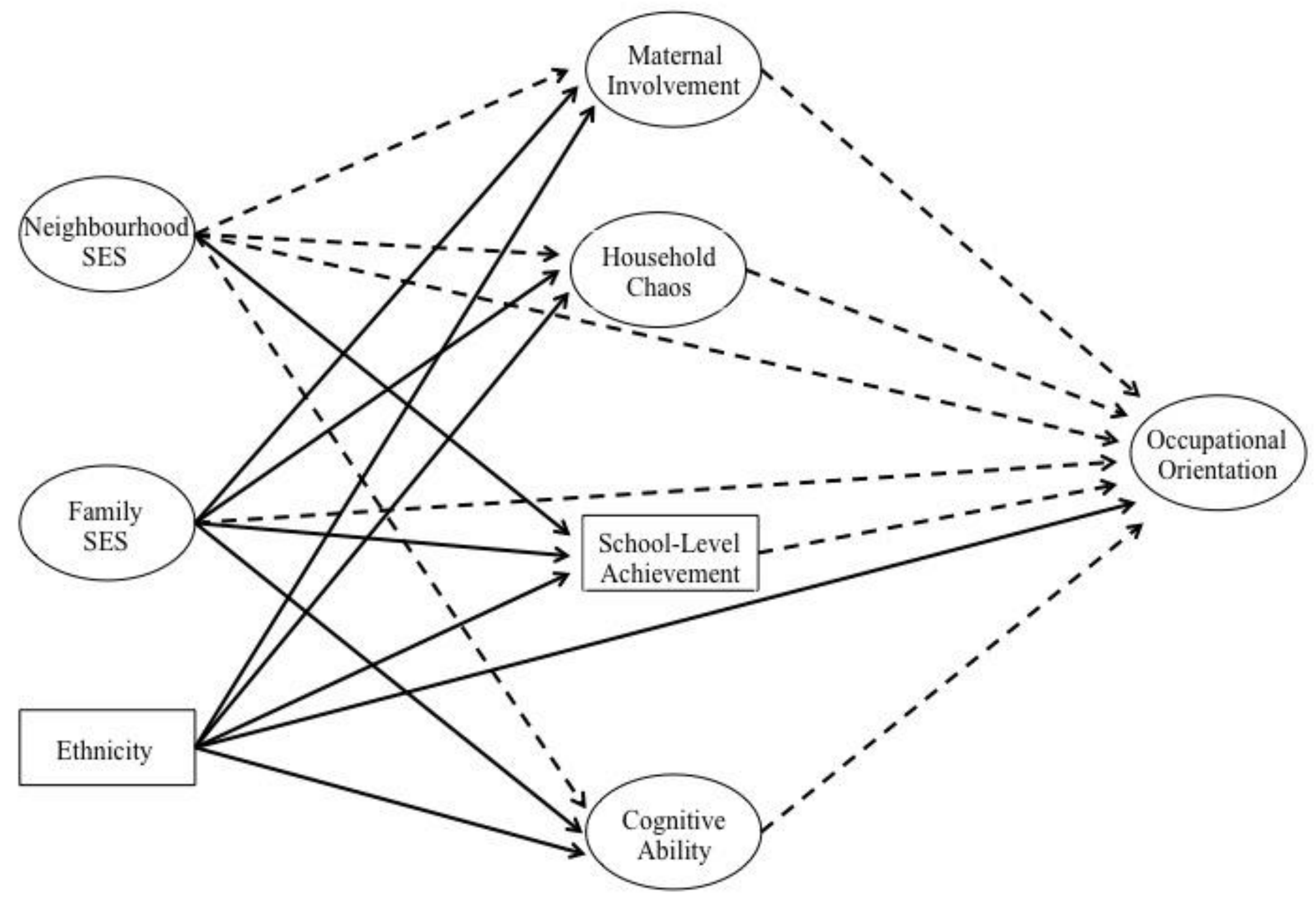

